\title{
What's Your Story? A Book Review of Leah Fowler's A Curriculum of Difficulty: Narrative Research in Education and the Practice of Teaching (2006)
}

\author{
Lisa A. Mitchell \\ Queen's University
}

\begin{abstract}
This is a book review of Leah Fowler's (2006) book entitled, A Curriculum of Difficulty: Narrative Research and the Practice of Teaching. This review was written as a complementary piece for Lisa A. Mitchell's (2010) paper entitled, A Continuum of Learning: Enhancing Connections Between Teacher-Candidates and Education Graduate Students Through a Narrative Framework, which can also be found in this issue of in education.
\end{abstract}




\title{
What's Your Story? A Book Review of Leah Fowler's A Curriculum of Difficulty: Narrative Research in Education and the Practice of Teaching (2006)
}

\author{
"As a conscious professional pedagogue, I find the need to tell my stories, \\ mostly to myself but sometimes to others, to make meaning of my existence” (p. 36).
}

Since I left the teaching profession to return to university to pursue a $\mathrm{PhD}$ in Education, I have been frequently asked to explain what exactly it is that I am doing with my life. "What's your story?" has become a recurring question asked by family members, close friends, former colleagues, and even the oddly curious stranger. More often than not, I answer with a succinct (and admittedly dull) explanation of the nature of formal research, the dream of becoming a published author, or the desire to be something more than "just a teacher." Sometimes, when I find myself without a great deal of time to unpack my personal career and life goals to a complete stranger (or even my mother!), I find myself defaulting to the rhetoric of course descriptions, grant applications, titles of academic papers, tossing around the word dissertation just for fun, or mentioning the names of people with whom I'm working with and learning from. And finally, after having exhausted all other explanations to no avail (or finding I lack the energy to even get that far), I default to the lowest common denominator of understanding that can occur between the education graduate student and the curious onlooker: "I'm a teacher and am pursuing a $\mathrm{PhD}$ at the same time" which is guaranteed to elicit the excited response of "Oh, you're a teacher!” (which is, of course, followed by the approving nod of understanding).

All of this begs the question: What does it really mean to be an educator who also engages in research beyond the confines of a traditionally imagined classroom? Why must a person be relegated to either this or that? Can a person be both-and? At first glance, Leah Fowler's book on narrative research seems like it's hand-tailored to serve those of us who are drawn to investigating the story of what we are doing in the education world. And on second glance, the book indeed proves itself to be just that: a carefully crafted opportunity for teacherresearchers to explore the complex stories of who we are as people and what we are doing as professionals.

\section{"Whenever I heard, read, or wrote narratives, meaning began to take shape. I could understand why people did what they did, that what happened to people made them the way they were" (p. 12).}

In her consideration of existence as both a teacher and researcher, Fowler discusses the benefits and perils of engaging with a narrative framework by not only describing the narrative process and its challenges, but also by interjecting narrative stories into the book from her own professional life in education - and indeed-from her life. The book focuses on difficulty in teaching practices with particular attention paid to teacher identity, or the professional teaching self. Thirteen original stories are presented as internarratives that not only link the chapters of the book together and facilitate the flow of writing and reading, but also constantly serve to reconnect theory with practice, academia with inspiration, and the teacher with the researcher. Given the fact that "people are storytelling beings who understand and impose order on [their] own and others' actions - organizing [their] experiences - by telling about them” (MacIntyre as cited in Gomez, Walker, \& Page, 2000, p. 733), it seems appropriate that Fowler takes advantage of this natural predisposition and demonstrates the potential for transformative learning by generously using her own stories of difficulty at the site of the teaching self as springboards for launching into the discussion of narrative inquiry. 
"The Hermes character is always present in the writing me, the reading me, the curriculum planning me, and the teaching me. From that Hermes character, I learn to hold multiple interpretations while always being aware of the trickster factor in any text-especially my own-where belief and intent can interfere with truths revealed and uncovered” (p. 121).

Fowler sets the bar high in terms of how narrative analysis can be implemented in a way that allows for a multiplicity of voices to be honoured and engaged with equal opportunity for criticism, (re)interpretation and reflection. Her proposed model for narrative inquiry includes seven orbitals of engagement; and while Fowler clearly states that her model of narrative inquiry should not be the model of narrative inquiry, she nonetheless presents an example of how others might construct narrative frameworks through emergent methods based on the legitimacy of lived experience as a source of knowledge and insightful learning. Throughout the text, we are reminded (both subtly and overtly) of our responsibility as educators to act as purposefully hermeneutic beings - ones who are open to interpreting and reinterpreting the events of our classrooms, the needs of our students, and the methods in which we negotiate our professional environments: "We need reflexive knowledge, skills, and attitudes to create meaningful work as trickster (hermeneutic) messengers of curriculum” (p. 151). Again, I would like to acknowledge here (as Fowler often does), that no narrative model of inquiry is ideal, no model is free from challenges, and no model should be used as a sort of panacea to achieving greater understanding in learning environments. Uninformed transplantation of such a model could be both unethical and highly problematic:

Narrative analysis is not for the faint of heart, certainly not for those seeking escape from quantitative research. Horizons unfamiliar will emerge, some daunting, some redemptive. A choice to engage in narrative should arise out of authentic research questions. It is the very difficulty itself revealed in emerging narrative that draws deeper study, luring the teacherly and writerly mind to more benthic zones of the self and profession. (p. 29)

Should we accept the challenge to engage in such a benthic endeavour by embracing the deeply unpredictable and emerging nature of narrative, this kind of inquiry does offer a framework of understanding that is highly flexible and rife with possibilities for creating transformative learning.

"With these seven orbitals - naïve storying, psychological de/reconstruction, psychotherapeutic ethics, narrative craft, hermeneutic enterprise, curriculum and pedagogy, and aesthetics and mindfulness in teaching - I continue to uncover and discover persistent questions and openings" (p. 185).

In Orbital One, ${ }^{1}$ Fowler asks us to consider ourselves as storytellers and to begin to recognize our natural predisposition to want to learn by giving voice to our experiences. Fowler writes: "Something happened; what is being told at the elemental story level?" (p. 30). This is the moment in which we find the initial courage to break our silence and risk discussing either our private or public stories with others in the hopes of provoking a socially constructed learning experience. The (re)telling of an experience, image, event, conflict, or puzzlement about a difficulty is usually where we start as we navigate our way into naïve storying, and where many of us choose to stop for fear of revealing too much about ourselves. As teachers, we are trained to withhold the subjective personal in favour of the objective professional. As researchers, we are asked to do something of the opposite, as we are immediately expected to begin situating ourselves in the research we undertake. Even in the very first stage of narrative inquiry, when we 
break ground on the risk of naïve storying, we must work to reconcile these two professional identities as we move forward with the interpretive experience.

In Orbital Two, ${ }^{2}$ Fowler asks us to begin unpacking the naïve story and work to recognize elements of effect and affect that exist within the storied context: "How can one think about the story, what emotions are evinced, what cognitive work of understanding more fully is called for?” (p. 30). What emotive responses might be triggered in the teacher-researcher, in the research participant, or in the reader? Fowler asserts that feeling is inextricably linked with the specific context at hand and the cognitive process of making sense, whether we are immediately aware of this truth or not.

In Orbital Three, ${ }^{3}$ Fowler's focus shifts from the facts and feelings of a story, towards an area of interpretation that is perhaps more fraught with difficulty: that of ethical considerations. Not only should teacher-researchers be considering general issues surrounding professional ethics and morality, but they should be acknowledging their own potential for doing harm in teaching and research: "Researchers attend to how to recall our shadows, our own capacity for projection and transference, and do honest work on our own psyche (spirit, soul, self)" (p. 30). This might be the level of narrative interpretation that cannot ever be fulfilled in its entirety. Many of us are unwilling (or perhaps unable) to acknowledge our own weaknesses and areas of vulnerability, and are not able to recognize the effect that our personal histories have on our current ability to interpret the experiences of others:

It is important to attend to the hidden truths in our selves, because of the ways they may affect our teaching relationships and curricula...we must as a profession and as individual teachers pay attention to losses, difficulties, and hidden truths, if we are to move forward into understanding meaning, and even poetics in teaching. (pp. 78-79)

Fowler clearly recognizes that this level of interpretation is a difficult, complex and troubling stage, and as a result, is one that requires ongoing care and constant revisiting. The work of ethical exploration is by definition, never complete.

Orbital Four, $\stackrel{4}{\text { is }}$ the section of the book in which Fowler introduces more fully her original concept of temenos: "This fourth orbital focuses on how the narrative construction safely holds everything in one place-people, events, relationships, setting, and difficulty or conflictlong enough to study it” (p. 30), with temenos being Fowler's own term for the kind of container that holds a story together (elements of convention, structure, and craft). Fowler offers the metaphor of force-field containers as a way in which to better understand the concept of temenos: "In the Greek sense of temenos, or crucible, a container of hot and dangerous materials that textually hold still the shards and images of difficulty long enough to examine” (p. 15). I am particularly drawn to this concept as an extension of close reading practices (Gallop, 2000) in which we investigate not only the seemingly more tangible elements of story-telling (conventions), but also seek to "see what we don't already know, rather than transforming the new into the old" (p. 11). It is up to each teacher-researcher to negotiate and interpret the narrative in her own way-there isn't only one prescribed method of envisioning the temenos since we have to acknowledge that there will never be one single static truth as long as individual context remains at the heart of each narrative.

Orbital Five,,-5 involves engagement in a careful interpretive exploration in which we seek a deeper message that lies hidden behind the obvious and attempt to uncover that which is either imbedded or contextual in nature: The ultimate goal of which is to reveal multiple layers of 
dynamic reinterpretation, as opposed to our previous search for the single, universal truth. Fowler asks: "What other interpretations can be made about the story in question?" (2006, pp. 30-31). The application of multiple lenses will no doubt reveal multiple outcomes and interpretations: Each of which is as legitimate and accurate as the next. This is the beauty of narrative inquiry! Hermes himself (from which hermeneutic was born) would have been the first to acknowledge the difficulty and potential for misinterpretation while delivering the message of the other: After all, how easy could it have been to accurately interpret the message of the gods and deliver it to the mortals? "The task of such a messenger was formidable: one who must first of all be conversant with all the words and referents of the gods, as well as their idiom and intent” (p. 120) and while Hermes' goal was to deliver the ultimate truth, the goal of present-day hermeneuticists might be better described as delivering the best possible truth(s) given the context and circumstances in which they find themselves and others.

Orbital Six,, "focuses on pedagogy and what can be learned and known about teaching from the narrative data” (p. 31). Fowler recaptures the feeling of melding both teacher and researcher back into a single identity. In what ways can we pragmatically apply what we've learned in our complex teaching and learning environments? Can we exist as both pragmatic teacher and idealistic researcher?

The narratives of self I write require me to pay a particular kind of focused and explicit attention to how I am living those questions in the daily vicissitudes with students, colleagues, administrators, significant others...concentrations of difficulty reveal themselves to show where thoroughgoing work is still needed. (p.149)

Orbital Seven, ${ }^{\underline{7}}$ “is a quiet place where we really know we are mortal and we freely set down all our narrative bundles and simply breathe in the miracle of existence as human beings" (p. 31). Fowler's words are both existential and practical as they direct teacher-researchers to become more whole and in turn, more holistic in their ongoing work: "Something in us does seem to want a more-ness in life: more meaning, more mattering, more beauty, more truth, more justice, more love" (p. 176). Why should the varied and complex experiences at the site of the teaching self be any different? I find myself returning to that place of inner questioning again every time I read this section of Fowler's book. What is my story as I continue down the continuum of learning as both a teacher and researcher, as both a graduate student and an educator? What is the story I recount to others? And ultimately, what is the story I am telling myself?

\section{"The difficulty of keeping up, as she was expected to, increased with time and distance. As the gap between her and the others increased she began to glance skyward, in vague remembrance of eagles” (p. 191).}

Fowler concludes her book with a short internarrative-The Small Brown Duck-which is reminiscent of whimsical childhood tales that contain a lesson, moral, or deeper meaning. How can the lesson be applied to new contexts? What can we come to understand through the story? What previously marginalized, unrecognized, or perhaps forgotten truths might be waiting for (re)discovery? I am pleased to report that Fowler's book is both academically substantial in its scope and dynamically creative in its conception. It successfully brings together the two worlds of the teaching self and the teacher-researcher into a single read. I have found myself reaching for this book when I need access to a clear academic resource on narrative methodology as often 
as I have found myself reaching for this book when I need to feel inspired about my dual roles as teacher and researcher and will no doubt continue to do so in the years to come.

"Startled by what I discover, uncover in the narratives, see in the narrative mirror, I return to breathing and Being” (p. 175). 


\section{References}

Fowler, L. C. (2006). A curriculum of difficulty: Narrative research in education and the practice of teaching. New York: Peter Lang Publishing, Inc.

Gallop, J. (2000). The ethics of close reading: Close encounters. Journal of Curriculum Theorizing, 17(3), 7-17.

Gomez, M. L., Walker, A. B., \& Page, M. L. (2000). Personal experience as a guide to teaching. Teaching and Teacher Education, 16, 731-747.

\section{Endnotes}

$\underline{1}$ Naïve Storying, pp. 36-44

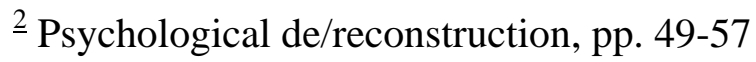

$\underline{3}$ Psychotherapeutic Ethics, pp. 76-83

$\stackrel{4}{4}$ Narrative Craft, pp. 96-111

${ }^{5}$ Hermeneutic Enterprise, pp. 119-142

6 Curriculum and Pedagogy, pp. 144-154

${ }^{7}$ Aesthetics and Mindfulness in Research and Teaching, pp. 175-190 